\title{
Percepções de Participantes Quanto ao Curso de Ativação de Processos de Mudança na Formação Superior de Profissionais de Saúde
}

\author{
Students' Perceptions of a Course on \\ Triggering Changes During Health Training
}

Alberto Durán González ${ }^{I}$

Marcio José de Almeida Fernanda de Freitas MendonçaII

\section{PALAVRAS-CHAVE \\ - Educação em saúde. \\ - Recursos humanos em saúde. \\ - Política de saúde. \\ - Educação permanente em saúde.}

\section{KEYWORDS \\ - Health education. \\ - Health manpower. \\ - Health policy. \\ - Permanent education in health.}

Recebido em: 01/05/2008

Aprovado em: 13/06/2008
${ }^{I}$ Universidade Estadual de Londrina, Paraná, Brasil.

${ }^{\text {II }}$ Faculdade Integrado de Campo Mourão, Paraná, Brasil.

\section{RESUMO}

Analisa-se a percepção de participantes do curso de especialização em ativação de processos de mudança na formação superior dos profissionais de saúde quanto à participação no curso. Trata-se de um estudo qualitativo, realizado com egressos do curso residentes no Paraná. A coleta de dados ocorreu de fevereiro a abril de 2007. Trabalhou-se com dados secundários, trabalhos de conclusão de curso (TCC) e dados primários, entrevistas semiestruturadas realizadas com autores de TCC que se caracterizassem como planos de ação. Como se tratava de planos de ação 21 TCC, suas autoras foram entrevistadas. Todos os participantes entrevistados eram do sexo feminino. O curso ajudou a identificar o desconforto vivenciado na realidade das participantes, forneceu ferramentas para a mudança e propiciou a experiência de utilização das mesmas. Entretanto, o curso de ativadores não conseguiu, após seu encerramento, manter a articulação desses novos atores do movimento pró-mudança.

\section{ABSTRACT}

This study analyzes the perceptions of participants in a graduate course on triggering processes of change during the training of health professionals. This was a qualitative study of course alumni residing in the State of Paraná, Brazil. Data were collected from February to April 2007. The secondary data included course monographs, and the primary data were from semi-structured interviews with the authors of monographs, considered as action plans. Twenty-one monographs were considered action plans, and the authors, all females, were interviewed. The course helped identify the discomfort experienced in relation to the participants' reality, provided tools for change, and fostered the actual use of these tools. However, upon conclusion, the course did not succeed in maintaining a link between these new actors and the pro-change movement. 


\section{INTRODUÇÃO}

Os ministérios da Educação e da Saúde lançaram, em 2004, o "AprenderSUS - o SUS e os cursos de graduação da área da saúde". Esta política buscava fortalecer as relações de cooperação entre instituições de educação superior e o sistema de saúde por meio da implementação das diretrizes curriculares e da adoção da integralidade como eixo orientador dos processos de formação' ${ }^{1}$.

No entanto, surgiu a necessidade de sistematizar e difundir as experiências acumuladas na área de mudança na formação em saúde para a efetiva implantação do AprenderSUS. Assim, o Departamento de Gestão da Educação na Saúde (Deges), vinculado à Secretaria de Gestão do Trabalho e da Educação na Saúde (SGTES), a Escola Nacional de Saúde Pública (ENSP) e a Rede Unida assumiram estes desafios. Emergiram três áreas de competência como resultado da sistematização: político-gerencial, educacional e cuidado à saúde. Foi na integração entre elas que se definiu o campo de atuação do ativador de processos de mudança².

Os atores envolvidos estruturaram o Curso de Especialização em Ativação de Processos de Mudança na Formação Superior de Profissionais de Saúde como estratégia de divulgação do conhecimento sistematizado. A abordagem dialógica de competência ${ }^{3}$, trabalhada durante o curso, visava à reflexão sobre as práticas profissionais, além da construção articulada entre os mundos do ensino e do trabalho com a sociedade.

O curso de ativadores utilizou metodologias ativas de ensino-aprendizagem, além da Educação à Distância (EAD) para as atividades não presenciais. Organizou-se em duas etapas: na primeira, com a formação de 99 tutores com o apoio dos orientadores de aprendizagem que trabalharam na sistematização das experiências acumuladas; na segunda, com a expectativa de formar mil especializandos com o apoio dos tutores formados previamente ${ }^{4}$.

O curso caracterizou-se como uma tentativa de ampliação e intensificação do movimento pró-mudança existente no cenário do ensino-aprendizagem. Visava-se à ampliação por meio da inserção de novos atores comprometidos com as novas propostas. A intensificação se daria pelo próprio modelo metodológico apresentado pelo curso. Esse modelo buscava a participação ativa e a construção coletiva do conhecimento. Por fim, os especializandos deveriam construir um plano de ação para uma proposta de mudança como Trabalho de Conclusão de Curso (TCC) $)^{4}$.

O Estado do Paraná sempre se destacou no cenário do movimento de mudança na formação em saúde e, em muitos aspectos, foi referência para diversas propostas anteriores de mudança. Cabe ressaltar que essas experiências não estão dis- persas pelo Estado, restringem-se a três ou quatro cursos de graduação que possuem um acúmulo importante e consistente quando se trata de processos de mudança e, principalmente, metodologias ativas ${ }^{5}$.

O curso de especialização apresentou-se como uma proposta coletiva e articulada, priorizando as experiências regionais, além de estimular e subsidiar a proliferação de processos de mudança na formação em saúde de forma pulverizada e nacional ${ }^{4}$. Dessa forma, torna-se fundamental para o movimento de mudança conhecer a percepção dos sujeitos envolvidos no curso.

A proposta deste estudo foi construir um conhecimento amplo, reflexivo e profundo, sem a pretensão de determinar soluções ou esgotar o assunto. Como não se trata de um fenômeno estático e pontual, busca-se contribuir com a socialização das experiências apresentadas pelos egressos do curso, desvelando a multiplicidade de fatores e de cenários.

Este artigo tem como objetivo analisar a percepção de egressos do Paraná quanto à participação no curso de ativação de processos de mudanças.

\section{MÉTODO: O CAMINHO PERCORRIDO}

Este artigo fez parte de um estudo cujo objetivo foi analisar a percepção dos paranaenses que participaram do curso de especialização e as mudanças que estão em processo de implantação, as estratégias utilizadas, as dificuldades e as facilidades encontradas.

Optou-se pelo método de pesquisa qualitativa, que pode ser caracterizado pela imersão do pesquisador no contexto e a perspectiva interpretativa de condução da pesquisa ${ }^{6}$ pelo pesquisador intérprete da realidade ${ }^{7}$ e como uma detalhada tentativa de compreensão de significados e características situacionais apresentadas pelos entrevistados ${ }^{8}$.

Neste sentido, entende-se que a pesquisa qualitativa abre maiores possibilidades de compreensão da experiência do novo ator, o ativador, frente à ativação de processos de mudança em seu cenário regional.

Escolheu-se trabalhar com dados secundários: os Trabalhos de Conclusão de Curso (TCC), referentes ao curso de especialização, e dados primários, as entrevistas realizadas com os autores dos TCC que foram categorizados como planos de ação.

Inicialmente, solicitou-se à ENSP e à Rede Unida, organizadoras do curso, a lista dos especializandos e tutores que concluíram o curso e que residiam no Paraná.

De posse dessas informações, deu-se início à primeira etapa da coleta de dados. Encaminhou-se aos 57 participantes listados como concluintes e residentes no Paraná, via e-mail, uma 
rápida apresentação do pesquisador e da pesquisa, o termo de consentimento livre esclarecido e o pedido para que enviassem o TCC referente ao curso. Após três tentativas de contato via $e$-mail e três por telefone, espaçadas nos meses de março e abril, finalizou-se o período de coleta dos TCC.

Do total de 57 participantes paranaenses no curso, 25 atenderam ao pedido de envio do TCC. Desses, 21 TCC se caracterizaram como planos de ação e foram selecionados para entrevistas. Entendeu-se nesta pesquisa que planejar é uma forma de organizar a ação e aproximar o objetivo da realidade. Portanto, os TCC selecionados foram aqueles que se caracterizaram como planos de ação que propunham mudanças por meio de ações. Não foram selecionados os TCC que relatavam apenas experiências anteriores à participação no curso, imaginando-se que estes se encontravam em um momento de avaliação e monitoramento. Também não foram selecionados os TCC que se restringiram à reflexão sem traçar ações, tendo-se em conta que estes se encontravam em um momento de insatisfação e análise de cenários.

Optou-se por entrevistas semiestruturadas, realizadas nos meses de maio e junho de 2007 nas cidades de residência das entrevistadas. Antes de iniciar as entrevistas, as participantes foram relembradas dos objetivos da pesquisa, da importância de seus depoimentos e da justificativa da utilização do gravador. Todas concordaram e assinaram o termo de consentimento.

O roteiro de entrevista continha questões que abordavam: 1) a participação no curso de especialização; 2) a integração entre as competências necessárias à formação do ativador; 3) as facilidades e dificuldades encontradas durante a implantação do plano de ação, 4) as estratégias utilizadas; 5) os efeitos que já podiam ser sentidos; 6) as perspectivas referentes ao movimento pró-mudança. Este artigo aborda apenas os resultados referentes à categoria "participação no curso de ativação".

Os TCC, os relatos do caderno de campo e as entrevistas foram identificados de acordo com a natureza da instituição à qual as participantes estavam vinculadas. As entrevistadas que tinham vínculo com Instituições de Ensino Superior Públicas foram identificadas com as letras IESPu, as vinculadas a Instituições de Ensino Superior Privadas, com as letras IESPr, e as vinculadas ao serviço, com ISP. As entrevistas em cada grupo foram numeradas, e cada sigla recebeu um número conforme a ordem da realização das entrevistas. Assim, a última entrevistada vinculada a uma instituição de ensino superior pública recebeu o código IESPu14.

Os TCC e as entrevistas foram analisados conjuntamente, ampliando os dados referentes à mudança e ao contexto a serem analisados. $\mathrm{O}$ corpus da pesquisa se constituiu dos relatos de observação descritos no caderno de campo, das transcrições das entrevistas e dos TCC.

Nesta pesquisa, optou-se pela Análise de Conteúdo por meio da Análise Temática. Segundo Bardin", esta técnica possibilita o estudo de motivações, atitudes, valores, crenças e tendências. Para Triviños ${ }^{10}$, seu uso revela o que, à primeira vista, não se apresenta com a devida clareza. Os recortes por tema foram realizados por meio do programa $\operatorname{Logos}^{11}$.

O projeto de pesquisa deste estudo foi analisado e aprovado por meio do parecer n⿳0 260/06 do Comitê de Ética em Pesquisa envolvendo Seres Humanos da Universidade Estadual de Londrina (CEP/UEL), atendendo à resolução 196/96².

\section{RESULTADOS E DISCUSSÃO}

As 21 entrevistadas eram do sexo feminino, sendo que 7 participaram do curso como tutoras e 14 como especializandas. Residiam em seis cidades paranaenses. Dentre elas, 14 tinham vínculo com instituições de ensino superior públicas, 4 estavam vinculadas a instituições de ensino superior privadas e 3 ligadas aos serviços de saúde. Londrina foi a cidade paranaense com maior participação tanto no curso quanto na pesquisa.

A Enfermagem esteve presente com 9 participantes - pouco menos de $43 \%$ das participantes -, sendo que 5 participaram como tutoras (Tabela 1). Isto demonstra a importante evolução conseguida pela Enfermagem. Apenas uma assistente social e a terapeuta ocupacional não atuavam como docentes em alguma instituição de ensino, sendo que esta última atuava como preceptora de estudantes.

TABELA 1

Caracterização dos sujeitos da pesquisa quanto à profissão

\begin{tabular}{lcc}
\hline \multirow{2}{*}{\multicolumn{1}{c}{ Profissão }} & \multicolumn{2}{c}{ Número de participantes } \\
\cline { 2 - 3 } & $\mathbf{N}$ & $\%$ \\
\hline Enfermagem & 9 & 42,8 \\
Fisioterapia & 3 & 14,3 \\
Serviço Social & 3 & 14,3 \\
Odontologia & 2 & 9,4 \\
Medicina & 1 & 4,8 \\
Nutrição & 1 & 4,8 \\
Psicologia & 1 & 4,8 \\
Terapia Ocupacional & 1 & 4,8 \\
Total & 21 & 100,0 \\
\hline
\end{tabular}

Os cursos de Enfermagem e de Medicina apresentam maior acúmulo e consequente destaque nas mudanças curriculares $^{13}$. O número expressivo de enfermeiras envolvidas na pesquisa acompanha os dados nacionalmente levantados pelos organizadores do curso ${ }^{14}$. 


\section{Participação no curso de ativação}

\section{O primeiro contato com o curso}

O primeiro contato com o curso despertou diferentes percepções sobre o processo de formação dos ativadores de mudança. Para aquelas que já estavam inseridas no movimento pró-mudança na formação e, portanto, já tinham contato com processos de mudança, o momento vivenciado estava desfavorável. As participantes relataram dificuldades na articulação dos avanços, esgotamento, cansaço e até mesmo um momento de "saída de cena de todo esse processo" (IESPu03).

O momento desfavorável foi entendido como aquele em que as dificuldades estavam mais presentes que as facilidades, dificultando o avanço mesmo com o uso de estratégias para contornar essas barreiras.

Embora o curso tenha surgido num momento de estagnação ou de avanço restrito, as participantes o reconheceram como uma oportunidade de saída da "aldeia cristalizada, muito instituída e inflexível" (IESPu02) e para contribuir com ações inovadoras nos cursos.

O curso veio em um momento difícil profissionalmente e pessoalmente, mas não poderia deixar de fazer. (ISP02)

Mais do que participar, esse grupo sentia a necessidade de contribuir com o curso por meio de suas experiências e avanços.

Fui porque achei que tinha muita coisa para contribuir, muita coisa para contar e que eu devia fazer isso. Independentemente de estar em um momento de retrocesso em minha instituição. (IESPu03)

Esta atitude demonstra o compromisso com a transformação. Segundo Morin ${ }^{15}$, a reforma na educação se inicia com a reforma dos educadores. Freire ${ }^{16}$ apresenta que apenas o homem comprometido é capaz de agir e refletir. Estas informações nos indicam que a transformação está em progresso e que o curso objetivava ampliar essa reflexão e, consequentemente, o compromisso com a mudança na formação superior em saúde.

O curso também foi visto como uma oportunidade de articulação entre as pessoas que almejavam a mudança na formação superior de profissionais de saúde.

Foi muito prazeroso, principalmente por encontrar pessoas envolvidas e compromissadas. (IESPu01)
[...] foi um privilégio estar ali, que deveria ser transformado em um direito de todo docente [...]. (IESPu02)

Diferentemente, para aquelas que não estavam inseridas e nunca haviam tido contato com processos de mudança na formação, o curso surgiu como uma tentativa de articulação entre o Ministério da Saúde e entidades comprometidas com a educação superior em saúde. Algumas participantes relataram que optaram pelo curso por se tratar de um curso específico na educação em saúde.

O grande número de desistências logo no início do curso neste segundo grupo demonstrou a não compreensão das metodologias ativas utilizadas no curso, o que resultou em desconfiança e desmotivação inicial. Entretanto, com a aproximação, as participantes compreenderam os objetivos do curso, a visão de ativação e a importância de cada um para o processo de mudança.

A desconfiança inicial e o sentimento de não se sentir parte do grupo - "como um peixe fora d'água" (IESPr02) - foram rapidamente transformados em surpresa com o método ativo de ensino-aprendizagem e a consequente mobilização.

Tivemos dificuldades de entender a proposta no início, mas depois foi muito gratificante. Foi uma pena que quem desistiu acabou perdendo. (IESPr02)

[...] a própria especialização foi um processo difícil para a gente pela metodologia aplicada. No início a gente ficava muito perdida porque também queria receber alguma coisa pronta. (IESPu13)

As dificuldades iniciais relatadas pelas participantes sugerem a influência da formação tradicional, que se preocupa mais com o aprender do que com o apreender.

Apreender é diferente de aprender. Segundo Anastasiou e Alves ${ }^{17}$, apreender significa compreender, assimilar, agarrar. A apropriação deve ser trabalhada de forma ativa pelo sujeito que deseja apreender. Já aprender se diferencia em seu sentido por se apresentar apenas como receber a informação de alguém. Portanto, seu êxito pode ser alcançado apenas com uma boa palestra que transmitirá a informação, sem se importar com o entendimento e a assimilação pelos receptores ${ }^{17}$.

Pogré ${ }^{18}$ afirma que a aprendizagem é um processo complexo em que cada sujeito ressignifica a realidade a partir de uma reconstrução própria e singular. As metodologias ativas 
de ensino-aprendizagem se baseiam nesta afirmação para trabalhar com o estudante e não para o mesmo. Essa atividade deve estimular o "aprender a aprender"19.

As participantes vinculadas às instituições de ensino relatam que o curso foi muito divulgado e que foram estimuladas a participar. Este estímulo não se deu sob a forma de apoio financeiro, mas as saídas para os encontros presenciais aconteceram com apoio dos demais docentes, que substituíam as participantes em suas atividades.

Recebi grande apoio e incentivo do departamento, mesmo com o vínculo empregatício frágil de professor auxiliar. (IESPu14)

Já as participantes ligadas ao serviço, principalmente em nível estadual, não receberam nenhum tipo de apoio e foram desestimuladas para a participação. Essa falta de apoio pode ter existido pelo difícil momento político vivenciado no período, sentido principalmente pelas participantes ligadas ao serviço. Todavia, aponta o distanciamento do serviço quanto à sua responsabilidade na formação.

A instituição não está dando muito espaço. [...] $\mathrm{Eu}$ por duas vezes fui para os encontros presenciais contrariando a chefia. (ISP02)

O serviço não se sente parte desse processo de discussão e não assume seu compromisso na formação, porém critica e culpa as instituições de ensino pela formação distanciada da realidade da prática. Feuerwerker ${ }^{20}$ aponta que a interação entre universidades e serviços de saúde deve ser umas das linhas fundamentais de trabalho para o movimento de mudança na formação. Deve-se agir politicamente na questão da formação profissional, criando incentivos à cooperação e esclarecendo o importante papel do serviço na formação dos novos profissionais. A formação deve ser ponto de pauta constante na agenda de gestores municipais, estaduais e federais.

Encontra-se aí parte da explicação do descompasso entre a formação dos novos profissionais de saúde e os princípios e diretrizes do SUS, que nada mais são que as necessidades dos usuários do sistema ${ }^{21}$.

As possíveis explicações para esse nítido descompasso da velocidade dos processos de mudança no serviço e na academia podem ser encontradas tanto na academia quanto nos serviços. Na academia, podem-se citar a gestão não comprometida, a atenção básica como aprendizagem marginal, o despreparo dos professores frente ao novo enfoque de aprendizagem, a difícil relação entre as diferentes profissões e a resistên- cia dos estudantes em relação ao contato com a comunidade. Nos serviços de saúde, podem-se enumerar a resistência dos profissionais às mudanças em processo, a visão de que a formação de profissionais não faz parte da agenda de trabalho, o acréscimo de uma função, ensino, sem receber por isso, a estrutura física inadequada para acolher os estudantes, a resistência da população à presença do estudante no serviço e a possível identificação de fragilidades do serviço prestado ${ }^{22}$.

\section{Contribuições para a ampliação do movimento de mudança}

Todas as entrevistas revelaram que o curso contribuiu positivamente para as atividades que as participantes desenvolvem em suas instituições. As contribuições referem-se a: inserção no movimento de mudança na formação em saúde; identificação de insatisfações e subsídios para a mudança.

Quanto à inserção no movimento pró-mudança na formação em saúde, as participantes relataram que o curso confirmou e qualificou os avanços antes conquistados com muitas dificuldades e sem a devida teorização.

O curso era tido como "o oásis dentro de um deserto" (IESPu03). Reunia pessoas com pensamentos semelhantes que, isoladamente em suas instituições, sentiam a aridez e o terreno pouco fértil para a discussão.

Entender-se dentro de um grupo e de um movimento maior, além de diminuir o sentimento de solidão, mostrou a real possibilidade de sucesso da proposta, afastando-se do reducionismo do sujeito à sua ocupação.

O reducionismo niilista apresentado por Gadoti ${ }^{23}$ pode ser observado como a abnegação do sujeito perante a função do papel de educador. Na luta contra o reducionismo, o sujeito que busca modificar significativamente o curso das coisas se organiza com outros, que têm ideias semelhantes, explorando e estimulando oportunidades do momento. Nestas condições, o individual age de forma articulada com o coletivo. O coletivo é estimulado e alterado pelo individual e, em contraparti$\mathrm{da}$, retroatua sobre o individual e produz o indivíduo ${ }^{24}$.

Enquanto para um grupo o curso se mostrou como a continuidade dos trabalhos pró-mudança na formação, para os demais o curso proporcionou um despertar para a possibilidade da mudança.

O curso veio mostrar que existia uma saída, um outro jeito de se fazer, uma maneira de sair das mesmices do dia-a-dia que não mostram resultados. (IESPu02)

O despertar para mudança se deu com a identificação das insatisfações pessoais existentes com o processo de ensino- 
aprendizagem tradicional. Para a identificação das insatisfações, as participantes relataram a importância do afastamento da realidade cristalizada propiciado pelo curso.

O curso propiciou a observação da aldeia a partir de outra perspectiva, propiciou o estranhamento do cotidiano, a desterritorialização. (IESPu02)

Eu era muito ligada a especialidades. Bem naquela estratificação do saber. Isso me abriu a mente [...] (IESPu04)

As práticas presentes no cotidiano dos docentes são determinadas pelas práticas sociais, as quais são produtos das relações sociais. Quando uma prática social se estabiliza, se repete com certa frequência, ela é percebida como se fosse uma regra natural, e assim os sujeitos sentem dificuldades em mudar e até mesmo perceber falhas em uma prática ${ }^{25}$. O movimento de tentar se afastar, se colocar fora do processo, é algo importante para a percepção de insatisfações. Contudo, isso não deve eximir os sujeitos de vivenciar e refletir sobre suas práticas, pois, conforme $\mathrm{Ceccim}^{26}$, para produzir mudanças é preciso interagir com as práticas em concreto no espaço do trabalho.

$\mathrm{O}$ conflito entre realidade e ideias de mudança, quando valorizado e trabalhado, gera a necessidade de estratégias e ferramentas para implantar as ideias de mudança. Entretanto, o trabalho com o conflito, em geral, é difícil e doloroso ${ }^{23}$. Muitas vezes, as participantes relataram que "perderam o chão" e a "identidade de professora". Todavia, os relatos apontam que ter vivido isso durante o curso amenizou o sofrimento, pois, junto com o conflito e a autorreflexão, o curso apontava algumas possibilidades para a mudança.

Além de identificar as insatisfações, o curso propiciou o contato direto com novos subsídios para a mudança, entre eles, novas ferramentas, conhecimentos, sujeitos comprometidos e experiências. Mais do que apenas fornecer a teoria que subsidia esse novo jeito de fazer, o curso proporcionou a experiência de trabalhar com ferramentas para a implementação da proposta. $\mathrm{O}$ acesso a teorias que conferem consistência às propostas ajudou na articulação de implantação das mudanças. Apresentou aos envolvidos a relação entre o ensino integral, articulado, e a utilização destes conhecimentos na prática que se mostra complexa e integral.

Eu adorei, aprendi muito. A gente ouvia e falava muito lá. Tinha coisas que doíam e tinha coisas que davam raiva, mas coisas que fazem você pensar. (IESPr03)
Com esses subsídios, os envolvidos atingiram o auge dentro do tempo técnico, o que permitiu que evoluíssem para o tempo político. Giovanella ${ }^{27}$, trabalhando com os tempos citados por Mário Testa, destaca que o tempo técnico enquadra as tecnologias para a construção e aplicação do plano de ação, enquanto o tempo político trata do poder de convencimento e compreensão dos atores envolvidos com a implementação.

[...] me deu mais segurança para propor mudanças em minha aldeia e assumir a coordenação. (IESPu12)

A posse do método como instrumento de poder, autonomia e liberdade faz com que Gadoti et $\mathrm{al}^{28}$ trabalhem com a subdivisão entre educador reacionário e educador revolucionário. $\mathrm{O}$ educador reacionário caminha com o objeto de conhecimento pronto em mãos e utiliza o método para transferir o conhecimento. O educador revolucionário "[...] não se considera possuidor do objeto de conhecimento, mas conhecedor de um objeto a ser desvelado e também assumido pelo educando." ${ }^{28}$

Este contato direto com as metodologias ativas favoreceu a sensibilização dos ativadores quanto às dificuldades que os colegas apontavam durante a implantação das propostas de mudança. Possibilitou, a alguns ativadores, a aproximação com os colegas chamados resistentes à mudança, identificando as dificuldades destes como similares às sentidas pelos ativadores durante o curso, além de identificar sentimentos como a expectativa de receber os conhecimentos já sistematizados e prontos. A participação ativa na experiência foi relatada como um desafio, pela pouca experiência dada pela formação tradicional vivida pelas participantes.

Eu tenho sensibilidade para com os meus colegas que demonstram essa inquietação, porque eu também vivi isso. [...] Passa a ser uma atitude que te acompanha aonde você for. Seja no ensino, na gestão ou no serviço. (IESPu13)

O trabalho com os docentes deve sempre valorizar a experiência acumulada e se iniciar com ela. Entre as ações sugeridas por Cavalcanti ${ }^{29}$ estão: propor problemas, novos conhecimentos e situações sincronizados com a vida real; justificar a necessidade e utilidade de cada conhecimento, envolver alunos no planejamento e na responsabilidade pelo aprendizado; estimular e utilizar a motivação interna para o aprendizado. Enquanto a pedagogia deve se envolver com motivações externas para o aprendizado, como notas e premiações, a andragogia deve priorizar a motivação interna, como a satisfação 
pelo trabalho realizado, a melhora da qualidade de vida e a elevação da autoestima ${ }^{29}$.

O curso contribuiu para que as participantes entendessem a implantação do processo de mudança como uma ação estratégica, identificando aliados, obstáculos e estratégias para o avanço, buscando incentivos para a implantação e traçando estratégias para a manutenção da mudança, além de promover a articulação entre os envolvidos com a proposta.

Como o grupo que fez esse curso de ativadores é uma minoria no meio do contingente de professores das universidades, é essa minoria que carrega o bonde. (IESPu01)

A estratégia usada na implantação do plano de ação deve considerar os três momentos na mudança das ideias de um grupo: 1) descongelamento do sistema atual de ideias; 2) reestruturação do sistema em outras bases; 3) recongelamento do novo sistema de ideias e hábitos ${ }^{30}$. Bordenave e Pereira ${ }^{30}$ apresentam o primeiro momento como o mais desafiante. Relatam que o êxito na implantação de uma inovação metodológica depende em especial da estratégia utilizada pelo grupo inovador. Ressalte-se que as estratégias devem considerar em especial as pessoas envolvidas com a proposta, devem fornecer subsídios no nível técnico, na perspectiva cultural e política, além de possuírem uma perspectiva pós-moderna ${ }^{17}$.

As participantes envolvidas com experiências de mudança anteriores destacam a importância dada pelo curso às relações pessoais nos processos de mudança, a importância do "momento" de despertar dos sujeitos envolvidos e a importância de aproveitar o despertar coletivo proporcionado pelo curso. Esse despertar transformado em mudança na postura prática profissional possibilita mudanças e facilita a articulação para mudanças maiores que, muitas vezes, estão longe da governabilidade de cada um.

O curso foi instigante e provocador, mas acima de tudo foi um processo muito afetuoso. (IESPu14)

A mudança de atitude foi um resultado positivo proporcionado pelo curso. Possibilitou encarar as dificuldades do dia-a-dia com outra perspectiva, na qual se poderiam utilizar as ferramentas incorporadas.

Depois do curso ficou mais fácil lidar com os problemas. (IESPu07)

Sinto-me mais professora agora. A gente não tem formação de docência e, quando chega na sala de aula, é uma enfermeira que está como professora. Agora me sinto um pouco mais preparada. (IESPr02)

Eu só entendo o impacto que a especialização teve em mim dentro desse movimento. Fora desse movimento, ela não teria o significado que teve. (IESPu13)

Esses discursos revelam que o curso também contribuiu para implementar a Educação Permanente em Saúde (EPS), pois as participantes passaram a utilizar problemas do cotidiano para oportunizar o aprendizado. Esse tipo de aprendizagem é denominado aprendizagem significativa. Segundo o Ministério da Saúde ${ }^{31}$, na aprendizagem significativa ocorre a produção de sentidos, uma vez que ela utiliza o dia-a-dia do trabalhador. A aprendizagem significativa ocorre quando o sujeito se sente motivado, isto é, tem o desejo de se apropriar de novos conhecimentos e quando os conhecimentos prévios do trabalhador e sobre o contexto local são considerados ${ }^{32}$. Este tipo de aprendizagem propõe que a transformação das práticas dos profissionais esteja alicerçada na reflexão crítica sobre as práticas exercidas no trabalho.

O curso também possibilitou aglutinar pessoas com interesses similares, permitindo a expansão da rede de contatos. Mobilizou novos atores e lideranças para intervir nas políticas postas e avançar na mudança. Possibilitou visualizar outros cenários de educação. Potencializou reflexões e ações pró-mudança e abriu perspectivas de avanços. Entretanto, o curso não conseguiu inserir o ativador no movimento pró-mudança. Isto porque ele não dispõe de uma estrutura de apoio. Ao contrário do facilitador de EPS e da Política de EPS, que contam com os Polos de EPS, o ativador saiu do curso e voltou a se isolar em sua aldeia.

A articulação dos ativadores é muito virtual para os problemas concretos que se encontra depois. (IESPu14)

A falta de inserção do ativador no movimento pró-mudança talvez tenha feito com que todo esse processo de formação fosse considerado apenas um curso descolado e não uma estratégia dentro de um movimento de mudança na formação. É importante trabalhar este ponto por trazer um fato intrínseco: o curso acabou, mas o movimento continua. Com isso, discute-se a desmobilização dos atores envolvidos no processo.

O curso foi como uma fonte de energia e incentivo para a mudança. O problema é que, com o fim 
do curso, as pessoas sentem que essa fonte secou, acabou. Isto reflete a não inserção dos ativadores no movimento de mudança. (IESPu08)

Contribui muito. Só acho que não podia morrer assim. (IESPu13)

\section{Percepções sobre o trabalho em grupo}

O curso se organizou com a divisão em quatro grandes núcleos distribuídos geograficamente. Os participantes paranaenses foram distribuídos entre os 40 pequenos grupos do núcleo São Paulo, que aglutinavam os participantes da Região Sul e parte dos participantes da Região Sudeste ${ }^{4}$.

Os relatos confirmam que a diversidade de experiências e pessoas nos grupos permitiu intensa troca e interação, processo possibilitado pela similaridade dos problemas vivenciados nas diversas realidades. A compreensão do problema do outro e o planejamento de estratégias para vencer as dificuldades eram exercícios e possibilidades que poderiam ser usados na realidade de cada um.

O meu grupo era bem interdisciplinar. [...] As experiências eram distintas a princípio, porém se encontravam nesse pensar integrar. (ISP01)

Antes eu não via, nem imaginava que outros cursos de Odontologia poderiam estar enfrentando as mesmas dificuldades que a gente. (IESPu06)

As participantes ressaltam a importância da liberdade dada aos grupos de trabalho para que cada um evoluísse em seu próprio ritmo, contemplando os itens programados para todo o curso. Em contrapartida, relatam um sentimento de angústia e um pouco de receio por não terem as ações nos grupos mais sistematizadas a priori.

Para $\operatorname{Costa}^{33}$, o ato de trabalhar com o novo pode gerar insegurança e resistência, que, muitas vezes, podem ser explicadas pela comodidade com o processo já adaptado. Isto foi observado por algumas participantes que, além de expressarem receio do novo, identificaram as raízes desse sentimento na formação tradicional que vivenciaram. Mas, para conquistar avanços, deve-se trabalhar o conflito e construir o conhecimento a partir da realidade dos participantes.

Diferentemente do pensamento simplificador, presente na concepção tradicional de ensino-aprendizagem, o pensamento complexo concebe a realidade natural e social como um fenômeno dialético permeado de incertezas ${ }^{24}$. Observa-se esta trama desprendendo-se dos hábitos fragmentadores e aceitando o desafio do diferente.

A dificuldade e a falta de hábito de trabalhar em grupo, manifestadas por algumas participantes, foram entendidas como fragilidade em se expor. Porém, assim que se sentiram à vontade com o grupo, essas dificuldades foram superadas, e o trabalho em grupo trouxe ainda mais entusiasmo para mudar. Essa dificuldade foi identificada como consequência do isolamento propiciado pela especialização que individualiza a construção do conhecimento.

[...] eu vejo que a especialidade parece ser muito você. Envolve você, necessita você se aprofundar, ir só em busca daquilo. Os ativadores me mostraram que eu posso trabalhar de uma forma mais socializada e ampla. (IESPu04)

As participantes relataram que no início não se tinha um grupo, mas, sim, um apanhado de pessoas com alguns pensamentos similares. Foi preciso tempo para que essa reunião de pessoas constituísse um grupo. Assim, os integrantes conseguiram interagir, trocar e crescer não só como grupo, mas também como indivíduos.

O individualismo presente na docência universitária é apontado por Petra et al. ${ }^{34}$ como um reflexo da organização do currículo estruturado em disciplinas. Segundo Zabalza ${ }^{35}$, esta organização gera uma intensa autonomia ideológica, científica e didática que se torna uma grande barreira para qualquer processo que tenda a romper a situação atual.

O trabalho coletivo exige a humildade e a habilidade de conversar, entendendo-se que essa "conversa" constitui uma abertura para mudar junto com o outro. Somente com essa abertura a reunião de pessoas constituirá um grupo e poderá atingir todas as potencialidades de avanços proporcionadas pelo trabalho em grupo ${ }^{17}$.

A homogeneidade num grupo dá a falsa impressão de unanimidade, a qual inibe a dúvida, a crítica e, por fim, o crescimento, teoricamente proporcionado pelo trabalho em grupo ${ }^{36}$.

O trabalho a partir das demandas dos grupos e o afetuoso processo contribuíram para o bom relacionamento entre as pessoas e o excelente resultado coletivo. Essa ação cria uma cumplicidade entre os integrantes do grupo. (IESPu14)

Emergiram relatos sobre o cuidado dos coordenadores do curso em contemplar a diversidade na seleção dos participantes. Entretanto, alguns relatos identificaram que a distribuição dos participantes nos grupos dificultou a articulação de ativa- 
dores geograficamente próximos. A formação de novos grupos de ativadores de realidades próximas potencializaria os processos de mudança que estavam sendo implantados, mas eles não conseguiram se articular.

Como as pessoas nos grupos eram de regiões diferentes, isto dificultou a articulação dos ativadores de uma mesma região. (IESPu08)

Em contrapartida, esse processo de distribuição nos grupos foi elogiado por outra participante, que acrescenta um importante aspecto nesta discussão:

Isso criou uma imunidade para a gente no momento dos encontros, que era uma coisa fantástica e que você não tem aqui. Vai falar dos seus desafetos aqui para você ver. Semeie vento e espere a tempestade. (IESPu14)

Imaginava-se que após o curso os ativadores que vivenciaram processos semelhantes se reuniriam para articular suas propostas de mudança. Porém instituições que vivenciaram processos anteriores mostram relações pessoais desgastadas, o que dificulta a articulação entre os diversos ativadores. Instituições que não vivenciaram processos anteriores ou em que as relações pessoais estavam fortalecidas apresentaram maior integração entre os ativadores, mas essa integração ainda está distante do potencial possível numa articulação em rede.

Com o fim do curso, encerrou-se o trabalho coletivo e voltou-se ao trabalho individual e desarticulado. A comunidade virtual AtivAÇÃO, vinculada à Escola Nacional de Saúde Pública, é um dos poucos espaços de discussão para os ativadores, porém seu potencial ainda é pouco explorado. Mesmo com a evolução para um cenário escasso em oportunidades, inexiste um movimento dos próprios envolvidos para continuar com a troca de experiências.

Nenhuma participante relatou problemas com a comunicação entre os ativadores durante o curso, todavia houve vários relatos de dificuldades em manter esses contatos. Esta postura demonstra para os próprios envolvidos um sentimento de que os ativadores não foram devidamente inseridos no movimento pró-mudança e que ficam fechados em suas aldeias. Sendo uma grande dificuldade a sensibilização dos outros, parece não ser mais simples a mobilização contínua dos atores já sensibilizados.

\section{CONSIDERAÇÕES FINAIS}

O curso conseguiu despertar os participantes para a importância da mudança na formação, porém não conseguiu inserir esses novos atores no movimento pró-mudança. Eles foram ativados, mas não articulados. A não articulação desses sujeitos em amplas redes torna o movimento de mudança pouco profundo e com as limitações de governabilidade. Os sujeitos continuam isolados em suas aldeias, onde sentem dificuldades de avançar e não contam com o apoio que contavam durante o curso.

A realização do curso possibilitou identificar os profissionais envolvidos com o movimento pró-mudança. A desarticulação não impediu a apropriação de novos subsídios para a implementação de mudanças. Porém, infelizmente, os limitou. Mesmo motivados e qualificados, os ativadores se mostram pouco disponíveis. Todos ficam à espera de que outros atores assumam as atitudes iniciais, e, com isso, ninguém dá o primeiro passo para uma articulação em rede. Sujeitos hoje motivados com a nova possibilidade começam, novamente, a se desmobilizar devido às dificuldades encontradas e à falta de apoio.

Contudo, os subsídios para essa articulação estão presentes. Políticas públicas favoráveis à mudança podem hoje ser mais efetivas no estímulo à mudança, por conhecerem os diversos processos de mudança em desenvolvimento no País.

\section{REFERÊNCIAS}

1. Brasil. Ministério da Saúde. Secretaria de Gestão do Trabalho e da Educação em Saúde. Departamento de Gestão da Educação na Saúde. AprenderSUS: o SUS e os cursos de graduação da área da saúde. Brasília; 2004.

2. Feuerwerker LCM, Lima VV. Formação de ativadores de processos de mudança - uma estratégia do AprenderSUS. Olho Mágico. 2004; 11(4):15-8.

3. Ribeiro ECO, Lima VV. Competências profissionais e mudanças na formação. Olho Mágico, 2003; 10(2):47-52.

4. Fundação Oswaldo Cruz. Caderno do especializando. Brasília/Rio de Janeiro: Brasil. Ministério da Saúde/FIOCRUZ; 2005.

5. Almeida MJ, Pereira LA, Turini B, Nicoletto SCS, Campos JB, Rezende LR, Mello PL. Formação dos profissionais de saúde no Paraná e a implantação das diretrizes curriculares nacionais. 2005. Disponível em: URL: http://www. observatoriopr.com/biblioteca.

6. Kaplan B, Duchon D. Combining qualitative and quantitative methods in information systems research: a case study. MIS Quarterly, 1988; 12(4):571-86.

7. Bradley J. Methodological issues and practices in qualitative research. Library Quarterly. 1993; 63(4):431-49.

8. Richardson RJ. Pesquisa social: métodos e técnicas. 3 ed. São Paulo: Atlas; 1999. 
9. Bardin L. Análise de conteúdo. Lisboa: Edições 70; 1979.

10. Triviños ANS. Introdução à pesquisa em ciências sociais: a pesquisa qualitativa em educação. São Paulo: Atlas; 1987.

11. Camargo Jr KR. Apresentando LOGOS: Um gerenciador de dados textuais. Cad Saude Publica. 2000; 16(1):286-7.

12. Brasil. Ministério da Saúde. Conselho Nacional de Saúde. Resolução n. 196/96 de 10 de outubro de 1996. Aprova as diretrizes e normas regulamentadoras de pesquisas envolvendo seres humanos. Brasília; 1996.

13. Sakai MH, Nunes EFPA, Martins VL, Almeida MJ, Baduy RS. Recursos Humanos em Saúde. In: Andrade SM, Soares DA, Cordoni Jr L. Bases da Saúde Coletiva. Londrina: EDUEL, 2001.

14. Lima VV., editor. Curso de especialização em ativação de processos de mudança na formação superior de profissionais de saúde. Relatório Final. Rio de Janeiro: EAD/ENSP, 2007. 90 p. No prelo.

15. Morin E. Educação e Complexidade: Os sete saberes e outros ensaios. Almeida MC, Carvalho EA,. (Eds.). 3 ed. São Paulo: Cortez; 2005.

16. Freire P. Educação e Mudança. 12 ed. São Paulo: Paz e Terra; 1986.

17. Anastasiou LGC, Alves L P., editors. Processos de Ensinagem na Universidade. 6 ed. Joinville, SC: UNIVELLE; 2006.

18. Pogré P. ¿Como enseñar para que los estudiantes compendan? Diálogo Educ, 2007; 7(20):25-32.

19. Demo P. Desafios modernos da educação. 13 ed. Petrópolis: Vozes; 2004.

20. Feuerwerker LCM. Estratégia de mudança da formação dos profissionais de saúde. Olho Mágico. 2002; 9(1):16-8.

21. Merhy EE, Feuerwerker LCM, Ceccim RB. Educación Permanente en Salud - una estrategia para intervenir en la micropolítica del trabajo en salud. Salud Colectiva, 2006; 2(2):147-60.

22. Oliveira MS. O papel dos profissionais de saúde na formação acadêmica. Olho Mágico, 2003; 2(10):37-9.

23. Gadoti M. Educação e poder: introdução à pedagogia do conflito. 14 ed. São Paulo: Cortez; 2005.

24. Falcón GS, Erdmann AL, Meirelles BHS. A complexidade na educação dos profissionais para o cuidado em saúde. Texto \& Contexto Enf. 2006; 15(2):343-51.

25. Brasil. Ministério da Saúde. Secretaria de Gestão do trabalho e da Educação na Saúde. Departamento de Gestão da Educação na Saúde. Curso de facilitadores de educação permanente em saúde: unidade de aprendizagem - análise do contexto da gestão e das práticas de saúde, Brasília; 2005a.

26. Ceccim RB. Educação permanente em saúde: desafio ambicioso e necessário. Interface. 2005; 9(16):161-77.
27. Giovanella L. Ideologia e poder no planejamento estratégico em saúde: uma discussão da abordagem de Mario Testa. [Dissertação] Rio de Janeiro, Escola Nacional de Saúde Pública, 1989.

28. Gadoti M, Freire P, Guimarães S. Pedagogia: diálogo e conflito. 7 ed. São Paulo: Cortez; 2006.

29. Cavalcanti RA. Andragogia: a aprendizagem nos adultos. Rev Clínica Cirúrgica da Paraíba. 1999; 4(6):33-41.

30. Bordenave JD, Pereira AM. Estratégias de ensino-aprendizagem. 27 ed. Petrópolis: Vozes; 2006.

31. Brasil. Ministério da Saúde. Secretaria de Gestão do Trabalho e da Educação na Saúde. Departamento de Gestão da Educação na Saúde. A educação permanente entra na roda. Brasília; 2005b.

32. Brasil. Ministério da Saúde. Secretaria de Gestão do Trabalho e da Educação na Saúde. Departamento de Gestão da Educação na Saúde. Curso de facilitadores de educação permanente em saúde: unidade de aprendizagem - Práticas educativas no cotidiano do trabalho em saúde. Brasília; 2005c.

33. Costa NMSC. Docência no ensino médico: por que é tão difícil mudar? Rev Bras Educ Med. 2007; 31(1):21-30.

34. Petra PAXJ, Beijaard D, Wubbels T. Teacher's development of professional knowledge through action research and the facilitation of this by teacher educators. Teaching and Teacher Education, 2004; 20(6):571-88.

35. Zabalza MA. O ensino universitário: seu cenário e protagonistas. São Paulo: Cortez; 2002.

36. Rosa SS. Construtivismo e mudança. 9 ed. São Paulo: Cortez; 2003.

\section{CONTRIBUIÇÃO DOS AUTORES}

Alberto Durán participou de todas as fases de construção do artigo. Márcio Almeida e Fernanda Mendonça participaram das fases de idealização, discussão e organização do artigo

\section{CONFLITO DE INTERESSES}

Declarou não haver

\section{ENDEREÇO PARA CORRESPONDÊNCIA}

Alberto Durán Gonzalez

Universidade Estadual de Londrina, Centro de Ciências da Saúde, Departamento de Saúde Coletiva.

R. Robert Koch, 60. Departamento de Saúde Coletiva.

Vila Operária - Londrina

CEP.: 86038-440 PR

E-mail: betoduran_fbq@yahoo.com.br. 